\title{
Effect of Laser Shock Processing and Aluminizing on Microstructure and High-Temperature Creep Properties of 321 Stainless Steel for Solar Thermal Power Generation
}

\author{
Wei Li $\left(\mathbb{D},{ }^{1,2}\right.$ Huang Huang, ${ }^{1,2}$ Dongliang Xu $\mathbb{D}^{1,2}$ Jian Chen $\mathbb{D}^{1,},{ }^{1,2}$ Lu Zuo $\left(\mathbb{D},{ }^{1,2}\right.$ Guozhi Ma $(\mathbb{D})^{3}$

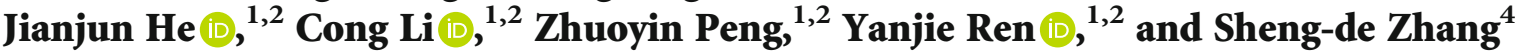 \\ ${ }^{1}$ Key Laboratory of Efficient \& Clean Energy Utilization, School of Energy and Power Engineering, Changsha University of Science \\ \& Technology, Changsha 410114, China \\ ${ }^{2}$ Hunan Province 2011 Collaborative Innovation Center of Clean Energy, and Smart Grid, Changsha 410114, China \\ ${ }^{3}$ College of Engineering and Designing, Hunan Normal University, Changsha 410006, China \\ ${ }^{4}$ Japan Electric Power Central Research Institute, Tokyo 240-0196, Japan
}

Correspondence should be addressed to Guozhi Ma; xiagy8520@126.com

Received 6 November 2019; Accepted 1 February 2020; Published 26 February 2020

Academic Editor: Pierluigi Guerriero

Copyright (C) 2020 Wei Li et al. This is an open access article distributed under the Creative Commons Attribution License, which permits unrestricted use, distribution, and reproduction in any medium, provided the original work is properly cited.

The aluminized layer of 321 stainless steel was treated by laser shock processing (LSP). The effects of constituent distribution and microstructure change of the aluminized layer in 321 stainless steel on creep performance at high temperature were investigated. SEM and EDS results reveal that aluminized coating is mainly composed of an $\mathrm{Al}_{2} \mathrm{O}_{3}$ outer layer, the transition layer of the $\mathrm{Fe}-\mathrm{Al}$ phase, and the diffusion layer. Additionally, LSP conducted on coating surface not only improves the density of the layer structure, resulting in an increment on the bonding strength of both infiltration layer and substrate, but also leaves higher residual compressive stress in the aluminized layer which improves its creep life effectively. Experimental results indicate that the microhardness of the laser-shocked region is improved strongly by the refined grains and the reconstruction of microstructures. Meanwhile, the roughness and microhardness of aluminized steel are found to increase with the laser impact times. On the other hand, the intermetallic layers, whose microstructure is stable enough to inhibit crack initiation, reinforce strength greatly. The anticreep life of aluminized sample with three times LSP was increased by $232.1 \%$ as compared to aluminized steel, which could attribute to the increased dislocation density in the peened sample as well as the decrease of creep voids in size and density.

\section{Introduction}

To meet increasing global energy demand in an environmentally sustainable manner, greater emphasis is being given to the development and dissemination of renewable energy technologies. Solar energy is an important renewable energy source that is expected to play a significant role in the future energy supply mix. Concentrated solar power (CSP) technology is an important option for acquiring solar energy which draws increasing attention during past several decades $[1,2]$. It is internationally believed that for every 1 percentage point increase in the annual average power generation efficiency of solar thermal power generation systems, the average power generation cost will be reduced by $5 \%$ to $8 \%$. Therefore, it is vitally significant to improve the power generation efficiency, reduce the cost, and increase service life of the solar thermal power generation system. However, as the key component of CSP, the heat exchange tube should be paid more attention [3-6].

Austenitic stainless steels (ASS) are commonly characterized by favorable ductility and excellent corrosion resistance [7-9]. AISI321, an austenitic stainless steel stabilized with titanium, is a promising material for load-bearing applications in solar thermal power generation, nuclear power reactors, boilers, pressure vessels, expansion bellows, and stack liners $[10,11]$. The heat exchange pipes made of AISI321 
TABLE 1: Chemical composition of 321 austenitic stainless steel.

\begin{tabular}{lccccccccc}
\hline Element & $\mathrm{C}$ & $\mathrm{Si}$ & $\mathrm{Mn}$ & $\mathrm{P}$ & $\mathrm{S}$ & $\mathrm{Cr}$ & $\mathrm{Ni}$ & $\mathrm{N}$ & $\mathrm{Ti}$ \\
\hline (wt.\%) & 0.035 & 0.38 & 1.08 & 0.028 & 0.003 & 17.02 & 9.06 & 0.045 & 0.22 \\
\hline
\end{tabular}

are prone to have creep damage under long-term hightemperature conditions, coupled with the combined effects of corrosive media and pressure within the pipe, to further accelerate pipeline failure and bursting.

Aluminizing can significantly improve the resistance of stainless steel to high-temperature oxidation, friction, and corrosive medium like atmosphere, hydrogen sulfide, seawater, and liquid metals $[12,13]$. Different techniques as chemical vapor deposition (CVD), hot dip aluminizing [14], pack aluminizing $[15,16]$, electrolytic deposition of $\mathrm{Al}$ from ionic liquids [17], and Ar-plasma deposition are applied for depositing $\mathrm{Al}$ on the surface of the steel. Among them, the powder pack aluminizing technique is widely used due to its advantages of producing a uniform dense layer on different shapes and sizes of specimens. Ref. [18-21] analyzed the phase composition of the aluminized layer and found the 321 stainless steel with a thicker layer showed a better resistance of oxidation and corrosion. On the other hand, the coating formed with the normal method of application is relatively porous with a multitude of defects and impurities. In particular, the $\mathrm{Al}_{2} \mathrm{O}_{3}$ film or $\mathrm{Fe}-\mathrm{Al}$ phase may crack, promoting microcrack propagation at a high temperature and stress, which causes the aluminized steel exhibiting a decrease in the creep life in high temperature. Moreover, the creep behavior of aluminized steel exhibits a higher creep rate and shorter creep rupture life than those of uncoated specimens [22, 23]. Ref. [24] also pointed out that brittle coatings with poor bearing properties were detrimental to the creep properties of the aluminized steel.

Laser shock peening (LSP) is an advanced surface enhancement method for metallic materials to enhance the resistance of creep, fatigue, and corrosion, which can delay the crack nucleation and expansion $[25,26]$. In the LSP process, high-amplitude shock waves are generated through rapid expansion of high-temperature plasma induced by the contact between high-power density laser pulse and the material surface. While the shock wave propagates into the material, plastic deformation occurs to a depth where the stress no longer exceeds the elastic limit of the material, which induces residual stresses throughout the affected depth $[27,28]$. Yella et al. reported that using an absorbent tape as a sacrificial layer was a good way to perform LSP on the stainless steel and it did not cause surface damage [29]. Vázquez Jiménez et al. pointed out that the best LSP path for extending the high-cycle fatigue life was perpendicular to the rolling direction [30]. Lu et al. found that the treated sample displayed better tensile properties such as stronger flow stress and higher ultimate tensile strength with an increasing LSP impact time [31]. To improve the creep resistance and anti-corrosion performance simultaneously, technology of aluminizing with LSP has been already investigated partially. Lai demonstrated that the fatigue life of material with aluminizing and LSP was increased visibly [32]. Ref. [33-36] also testified that the mechanical property of the aluminized steel was greatly improved by LSP.

In view of the above considerations, many researches mainly focused on the anticorrosion capability, LSP parameters, and the influence on fatigue behaviors. Nevertheless, the studies about high-temperature creep properties of the stainless steel with aluminizing and LSP is rarely reported. Therefore, in order to ensure the stable operation of stainless steel heat exchanger under actual working conditions, the effect of surface modification processes, aluminizing with LSP, on the microstructure and high-temperature creep properties of 321 stainless steel was investigated in this paper.

\section{Materials and Methods}

2.1. 321 Stainless Steel. The austenitic steel AISI 321 was procured commercially for this investigation. The result of elemental composition analysis is presented in Table 1.

2.2. Powder Pack Aluminizing. The pack powder mixture consisted of $68 \mathrm{wt} \% \mathrm{Fe}-\mathrm{Al}$ powder, $30 \mathrm{wt} \% \mathrm{Al}_{2} \mathrm{O}_{3}$ filler, and $2 \mathrm{wt} \% \mathrm{NH}_{4} \mathrm{Cl}$ activator. The samples were ground to \#2000 grit-sized $\mathrm{SiC}$ paper finish and cleaned thoroughly before placing inside the pack, and then, samples were kept inside the pack in an alumina crucible, which was subsequently covered with a lid. Pack aluminizing experiments were carried out in a KSL-1400X box-type sintering furnace, and samples cooled to room temperature after being heated at $950^{\circ} \mathrm{C}$ for $12 \mathrm{~h}$. The cross-sectional image of the coating layer is shown in Figure 1. The EDS and SEM results indicate that aluminized coating is mainly composed of an $\mathrm{Al}_{2} \mathrm{O}_{3}$ outer layer, the transition layer of the $\mathrm{Fe}-\mathrm{Al}$ phase (such as $\mathrm{Fe}_{3} \mathrm{Al}, \mathrm{FeAl}$, $\mathrm{FeAl}_{2}$, and a small amount of AlN), and the diffusion layer with the $\mathrm{AlFe}(\mathrm{Ni})$ phase and $\mathrm{AlCrFe}$ phase. In the case of aluminizing processes, there was a formation of surface layers of a new composition and structure. The formation of such a local transition zone in the form of individual areas or intermetallic compounds directly in aluminizing led to the fact that high-stress microcracks appear in this area and significant local overstresses cause loss of strength of the solid coating system in thermal deformation action on it.

2.3. LSP Treatment. The LSP was performed with the LAMBER-08 pulsed laser which is operating at a $1064 \mathrm{~nm}$ wavelength and delivering $7 \mathrm{~J}$ pulse energy in $20 \mathrm{~ns}$, with a $2 \mathrm{~Hz}$ repetition rate. The diameter of laser spot is $3 \mathrm{~mm}$, the overlapping rate is $50 \%$, and the laser power density is about $4.95 \mathrm{GW} / \mathrm{cm}^{2}$. In order to protect the surface of the metal material from direct laser burning and couple with the laser energy better, the black adhesive tape is selected as the impact protection layer. The constraining layer is water, to constrain the high-temperature plasma generated by the laser irradiation and increase the shock wave pressure [37]. 


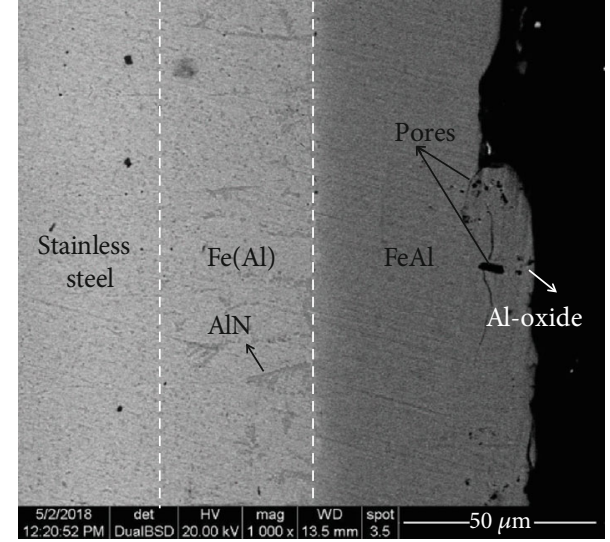

FIGURE 1: SEM section morphology of the coating layer formed after pack aluminizing at $950^{\circ} \mathrm{C}$ for $12 \mathrm{~h}$.

2.4. Surface Roughness and Microhardness. A JB-4C precision roughness tester with a $0.8 \mathrm{~mm}$ sampling length and a $2 \mathrm{~mm} / \mathrm{s}$ sensor movement speed was used to measure the surface roughness. 3D surface profiles of samples were observed by the VHX-1000 super-deep 3D microscopic system. The microhardness was tested with a 410MVA Vickers microhardness tester using a load of $300 \mathrm{~g}$ and a hold time of $15 \mathrm{~s}$.

2.5. High-Temperature Creep Experiment. Samples treated by different processes, such as aluminizing, aluminizing with single LSP impact, and aluminizing with LSP impacts for three times, were subjected to high-temperature tensile creep tests on a WDML slow tensile tester at the temperature of $620^{\circ} \mathrm{C}$ and the stress load range of $180-240 \mathrm{MPa}$. Creep tensile specimens with a gauge length of $24 \mathrm{~mm}$ and $4 \mathrm{~mm}$ thickness were made.

2.6. XRD and Microstructure. The surface phases of the aluminized steel with different times of LSP impact were analyzed by a TD3000 X-ray diffractometer (XRD). The Quanta 2000 environment scanning electron microscope (SEM) and the attached energy dispersive spectrometer (EDS) were used to examine the creep fracture.

\section{Results and Discussion}

3.1. Surface Roughness and Microhardness. Surface roughness plays a dominant role in affecting the creep performance and reflecting the collection characteristics of the material surface. Surface roughness is evaluated by three index, including contour arithmetic mean deviation $\left(R_{a}\right)$, contour maximum height $\left(R_{z}\right)$, and contour unit average width $\left(R_{\mathrm{ms}}\right)$, where $R_{a}$ can simultaneously reflect the microscopic geometrical features and the height of the convex peak [38]. If these rough peaks are equivalently approximated as microgaps, the stress concentration of the rough peaks can be calculated using the notch stress formula [39]:

$$
\sigma=2 k[1+\ln (1+m)]
$$

TABLE 2: Surface roughness values of the aluminized steel with different times of LSP impact.

\begin{tabular}{lcccc}
\hline Sample & $\begin{array}{c}R_{a} \\
(\mu \mathrm{m})\end{array}$ & $\begin{array}{c}R_{z} \\
(\mu \mathrm{m})\end{array}$ & $\begin{array}{c}R_{m s} \\
(\mu \mathrm{m})\end{array}$ & $\begin{array}{c}m \\
(\mu \mathrm{m})\end{array}$ \\
\hline Aluminizing & 0.952 & 7.174 & 0.0645 & 111.2 \\
Aluminizing+single impact & 1.856 & 10.813 & 0.0930 & 116.3 \\
Aluminizing+three impacts & 3.347 & 20.718 & 0.1667 & 124.3 \\
\hline
\end{tabular}

where $k$ is the material constant and $m$ is the ratio of $R_{z}$ to $R_{\mathrm{ms}}$. The larger the value of $m$ is, the greater the stress concentration is. Table 2 presents the surface roughness of specimens with different times of LSP impact. As can be seen, the roughness of the aluminized sample is $0.952 \mu \mathrm{m}$, and the roughness increases rapidly with the increase of impacts' times. The more the stress concentration is, the easier to generate microcracks, resulting in internal damage of the material. Nevertheless, the roughness is related to the laser absorption, namely, the overly smooth metal surface is not conducive to the absorption of laser [40].

The optical photograph and 3D surface profile for different conditions are shown in Figure 2. It can be seen from Figures 2(a) and 2(d) that the surface of aluminized samples is smooth and flat with regular dimples, and the average pit depth is $7.174 \mu \mathrm{m}$. The morphology of the aluminized sample with single LSP impact (Figures 2(b) and 2(e)) displays the existence of obvious pits and steps, whose shapes are square or circle. The shape of the pits depends on the contact pressure between the protective layer and the sample [41]. The average pit depth is $10.813 \mu \mathrm{m}$ with an increase of $50.7 \%$ and the deformation amount is $3.639 \mu \mathrm{m}$. The morphology of the sample after three impacts is shown in Figures 2(c) and 2(f). The plastic deformation was aggravated by the plastic loading wave. The depth of the pit is $20.718 \mu \mathrm{m}$ with an increase of $188.8 \%$, and the deformation amount is $13.544 \mu \mathrm{m}$. As the LSP time increases, the roughness and the degree of plastic deformation are alleviated, which attributes to the generation of surface pits predominately. Figure $2(\mathrm{~g})$ is the pulse sequence applied to treat the specimens. It consists of firing pulses in a zigzag-type scanning pattern, covering a total area of $24 \times 8 \mathrm{~mm}$ in the central zone of the specimens. A laser impact region with a diameter of $1 \mathrm{~mm}$ and a depth of $21.5 \mu \mathrm{m}$ can be observed on the aluminized samples after three LSP impacts, and the plastic deformation is one of the important indexes for evaluating the enhancement effect of LSP.

Figure 3 presents the microhardness of aluminized samples before and after LSP. The microhardness of the aluminized sample gradually increases with increasing distance from the penetrating layer to the surface, which could be imputed to intermetallic compounds formed in the penetrating layer mainly. In addition, the grain grows and the material softening phenomenon occurred during the hightemperature aluminizing process. Therefore, the hardness was found to be lower when the depth of the layer was measured to $180 \mu \mathrm{m}$. However, subjected to radial shock waves released by LSP, the surface of the aluminized steel would 


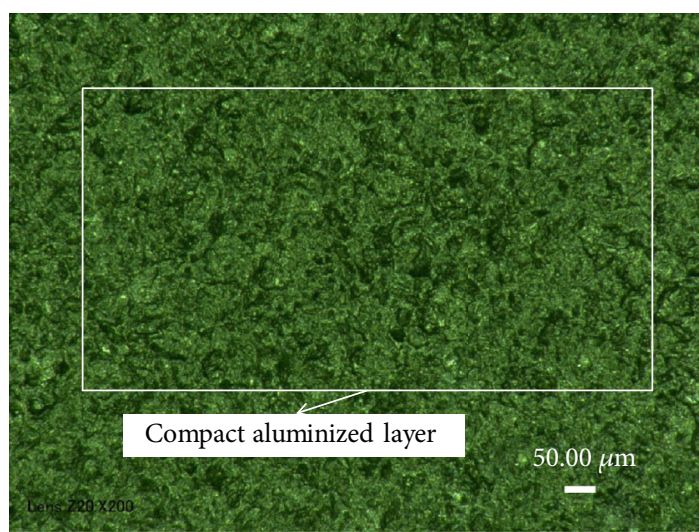

(a)

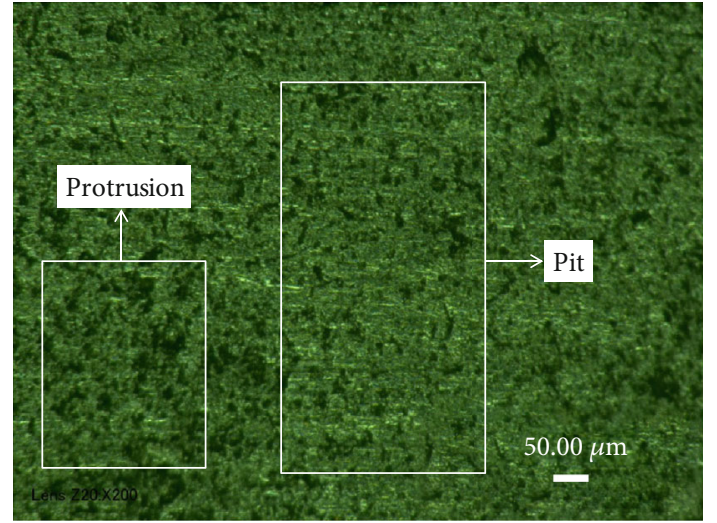

(c)

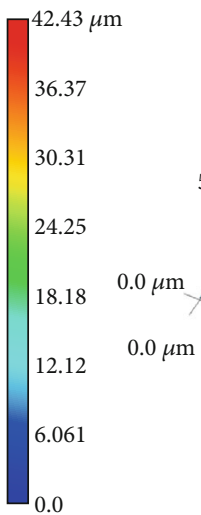

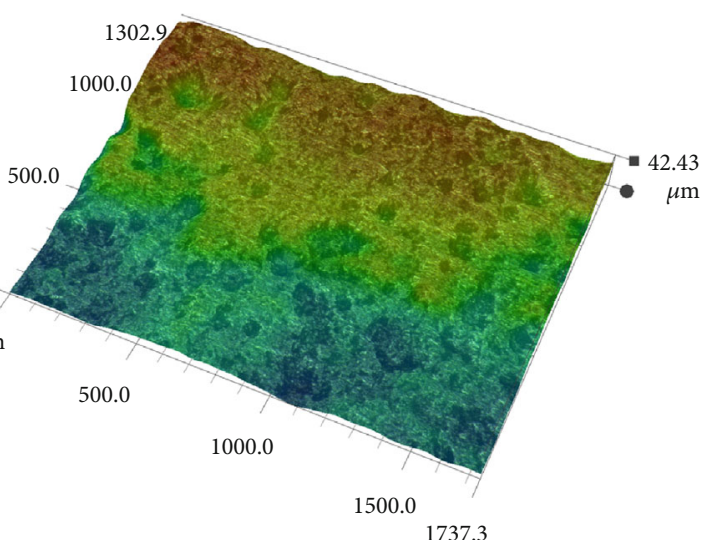

(e)

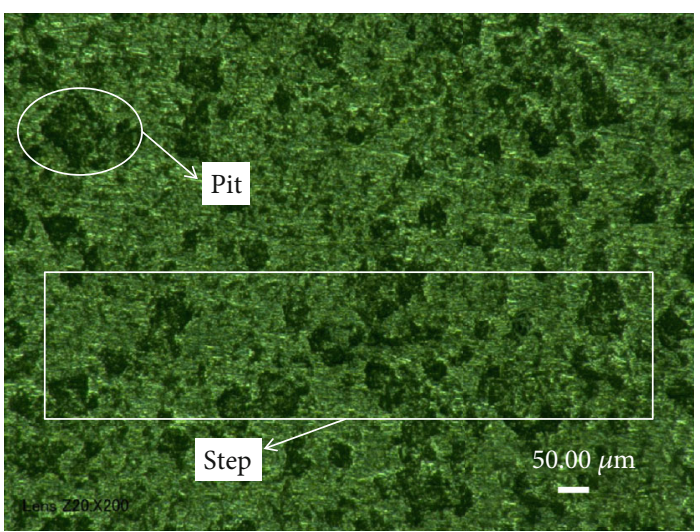

(b)

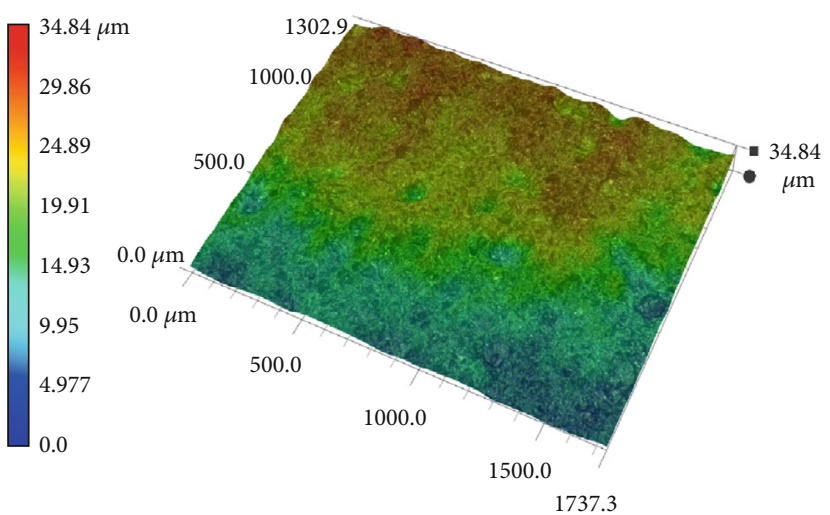

(d)
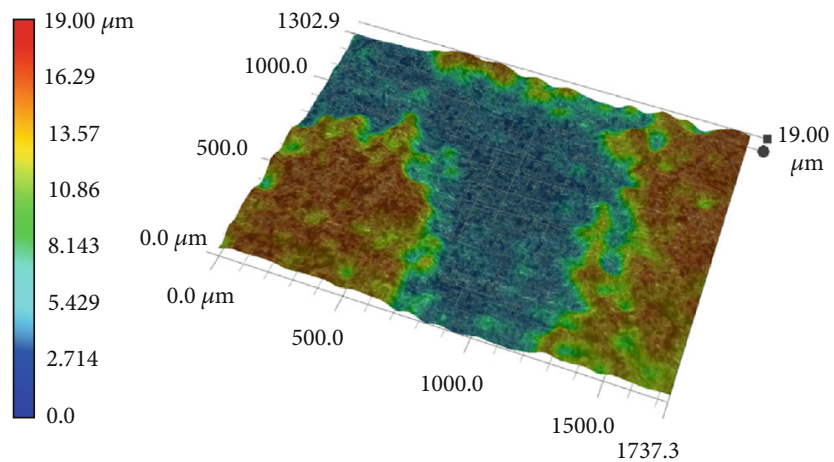

(f)

Figure 2: Continued. 


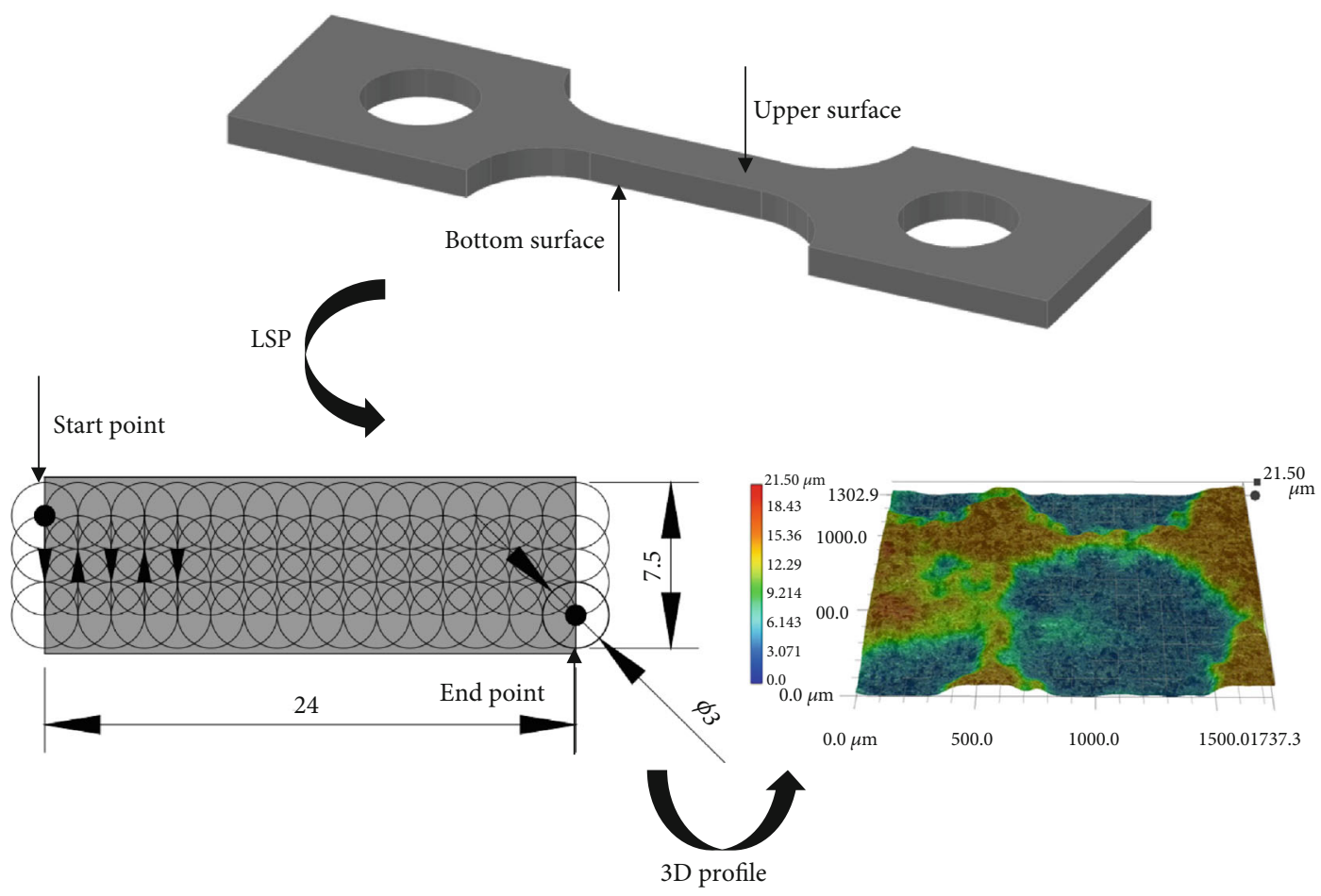

(g)

FIGURE 2: Optical photograph and corresponding 3D surface profile: (a) optical photograph of aluminized steel; (b) optical photograph of aluminized steel with single LSP impact; (c) optical photograph of aluminized steel with three LSP impacts; (d) 3D surface profile of aluminized steel; (e) 3D surface profile of aluminized steel with single LSP impact; (f) 3D surface profile of aluminized steel with three LSP impacts; and (g) scanning pattern and the enlarged 3D profile of the aluminizing with three LSP impacts sample.

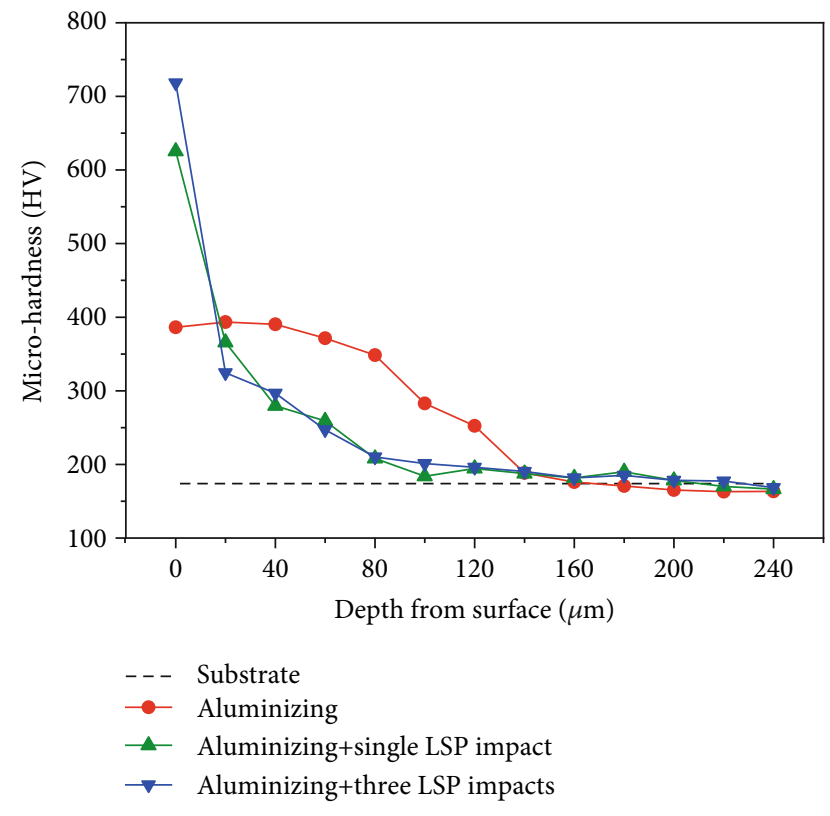

FIGURE 3: Microhardness variation along the depth of aluminized samples with different times of LSP impact.

generate severe plastic deformation, advancing the surface hardness of materials significantly. It is well known that plastic deformation will cause work-hardening effect and grain

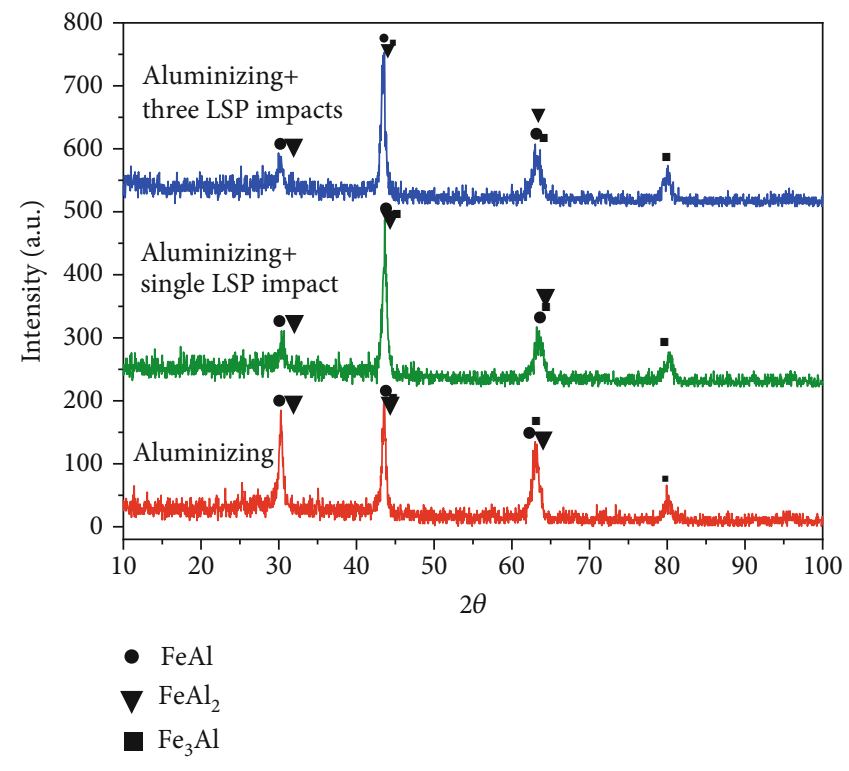

FIGURE 4: XRD spectra of the aluminized samples with different times of LSP impact.

refinement, thus increases the hardness of the work piece. Similar conclusions have been drawn from Ref. [42, 43]. As the number of impacts increases, the surface microhardness increases from $395 \mathrm{HV}$ of the nonimpacted sample to $625 \mathrm{HV}$ and $718.4 \mathrm{HV}$. Figure 4 is the XRD pattern of 
aluminized samples before and after LSP. There are mainly three phases, $\mathrm{FeAl}, \mathrm{FeAl}_{2}$, and $\mathrm{Fe}_{3} \mathrm{Al}$, and none of the new phase is observed after LSP. The position of the crystal surface is hardly changed, while the intensity of the diffraction peak is obviously reduced, and the full-width half maxima (FWHM) become larger. It illustrates that surface grains were refined after LSP, and the grain refinement phenomenon of three-time impact samples was more obvious than single-impact samples, which is consistent with the conclusion of the previous hardness enhancement mechanism.

3.2. Creep Curves. Figure 5 shows the high-temperature creep curves and creep rate curves of the aluminized steels with different times of LSP impact under a series of loading stress. It is observed that all the specimens have similar curve shapes to characterize three stages of typical creep behaviors, namely, the deceleration creep stage, stationary creep stage, and accelerated creep stage. The first stage of creep is shorter while the second stage of creep turns longer. As shown in Figures 5(a) and 5(d), aluminized samples enter the stationary creep stage within $10 \mathrm{~h}$. With the increase of loading stress, the time for samples to enter the steady-state phase is shortened and the creep rate and creep strain increases. When the applied stress reaches $210 \mathrm{MPa}$, the steady-state creep rate of the aluminized sample rises from $1.05719 \times$ $10^{-7}$ to $1.482204 \times 10^{-6}$ and the creep rupture time degrades from $206 \mathrm{~h}$ to $28 \mathrm{~h}$, indicating that the creep resistance of the material was remarkably affected by the stress. The creep curves of aluminized samples with single (Figures 5(b) and 5(e)) and three times (Figures 5(c) and 5(f)) LSP are similar, which implies that the three states of materials were remarkably affected by the external loads. Figure 6 represents the relationship between the applied stress and creep rupture time of the austenitic stainless steel treated with different surface modification processes and all results show that the creep rupture time is inversely correlated to the stress at the creep experimental temperature. At the same time, we found that the steady-state creep rate decreases and creep rupture time extends with the increase of impact times. The steady-state creep rate of specimens with single and three times decreases by an order of magnitude, and their creep rupture lives are increased by $42.8 \%$ and $232.1 \%$, respectively, when the applied stress is $210 \mathrm{MPa}$, which clearly demonstrates that the high-temperature creep resistance of aluminized samples is significantly improved by LSP technology.

In the stationary stage, the effective dislocation density remains unchanged to keep a balance between the material recovering and hardening due to the constant external stress and high-temperature environment. Consequently, the stationary creep rate with the smallest value and the simplest deformation mechanism is the key parameter to reflect the creep behavior of the material. Figure 7 displays that the applied stress is positively relevant to the minimum creep rate of the steady-state creep region. The minimum creep rate and applied stress are well-known to be related by a power law as presented in

$$
\dot{\varepsilon}=A_{x} \sigma^{n} \exp \left(-\frac{Q_{c}}{\mathrm{RT}}\right),
$$

where $\dot{\varepsilon}$ is the stationary creep strain rate, $A_{x}$ is a complex constant correlated to the material structure, $\sigma$ is the applied stress, $n$ is the creep stress index, $Q_{c}$ is the creep apparent activation energy, $R$ is the molar gas constant $(R=8.314 \mathrm{KJ} / \mathrm{mol})$, and $T$ is the absolute temperature. Equation (2) on both sides conducts the logarithmic processing to obtain Equation (3). When the creep temperature $T$ is constant, $\ln \varepsilon$ and $\ln \sigma$ have the linear relationship of slope $n$ (Equation (4)) as follows:

$$
\begin{aligned}
\ln \dot{\varepsilon} & =\ln A_{x}+n \ln \sigma-\frac{Q_{c}}{\mathrm{RT}}, \\
n & =\left(\frac{\partial \ln \dot{\varepsilon}}{\partial \ln \sigma}\right)_{T} .
\end{aligned}
$$

Figure 8 exhibits the logarithmic relationship between the steady-state creep rate and the applied stress. It can be concluded that the $n$ values of aluminizing and aluminizing composite single and three-time LSP samples are 13.73, 19.71 and 23.13 , respectively. The matrix alloy is 321 austenite stainless steel, and the values 3 and 5 of stress exponent stand for two important creep types of solid solution. When $n \leq 3$, the stress exponent has a typical value of 3 , this signifies that the creep behavior is very different from that of a pure metal, which is called the first class of alloy-type creep; when $n=4-7$, its typical value is 5 , which indicates that the creep behavior is similar to that of pure metals, which is called the second pure metal creep; when $n \geq 8$, the steady-state creep behavior can no longer be described by power-law equations [44]. Ref. [45] points out that if a metallic had a larger apparent stress exponent, the metal may have a higher creep stress threshold, which can predicate that the aluminizing composite LSP material has a higher creep stress threshold and better creep resistance.

3.3. Fracture Morphology. The creep macroscopic fracture appears the necking phenomenon while the crack-like plastic deformation occurred near the typical ductile fracture. The fracture existence of clear cross-section grains with strong sense of third dimension testifies that it belongs to intergranular fracture. The area shrinkage of impacted specimens is higher than that of nonimpacted specimens, implying that the impacted specimens have a better plasticity. It can be seen from Figure 1 that there are some defects on the coating layer, such as coarse second-phase particles (AlN) and pores. During the high-temperature creep process, the abundant intracrystal cross slips glided to the pore position or grain boundary lattice defects caused by the residual tensile stress, resulting in plenty of micropores. These micropores continued to converge into cracks which caused the expansion and separation of grain boundaries under the tensile stress. According to the SEM morphology of fracture surfaces and the EDS analysis of Figure 9, it can be distinguished that the fracture surface of aluminized steels can be roughly divided into three layers: the outer layer $(\mathrm{FeAl})$, the transition layer (mainly composed of $\mathrm{FeAl}_{2}$ and $\mathrm{Fe}_{3} \mathrm{Al}$ ), and the 


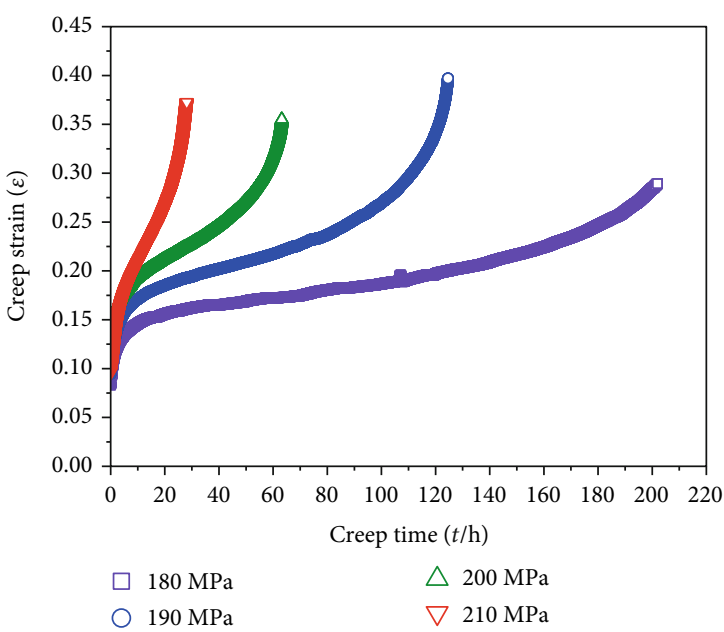

(a)

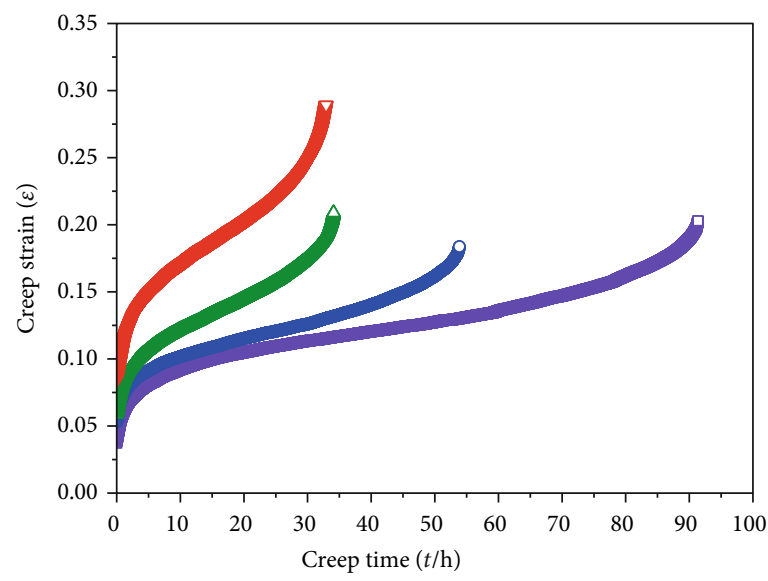
$\square 210 \mathrm{MPa}$
$\triangle 220 \mathrm{MPa}$
○ $215 \mathrm{MPa}$
$\nabla 225 \mathrm{MPa}$

(c)

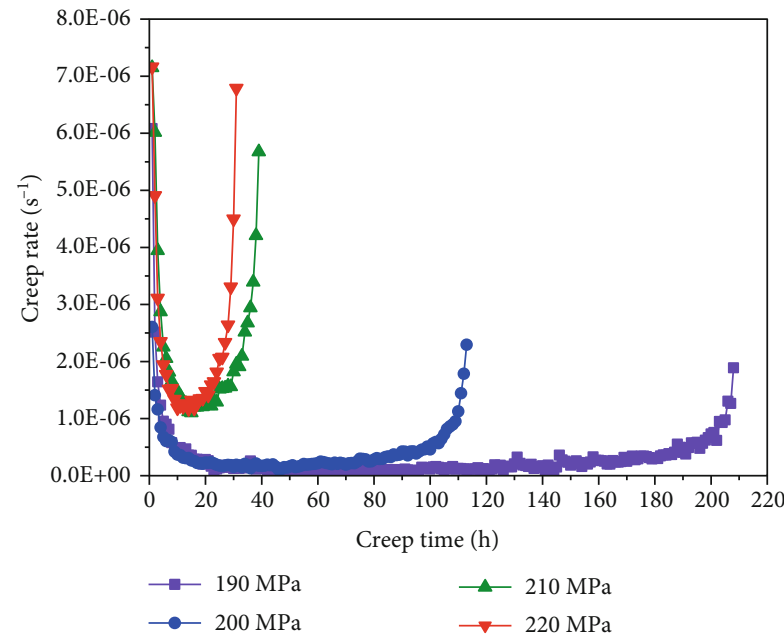

(e)

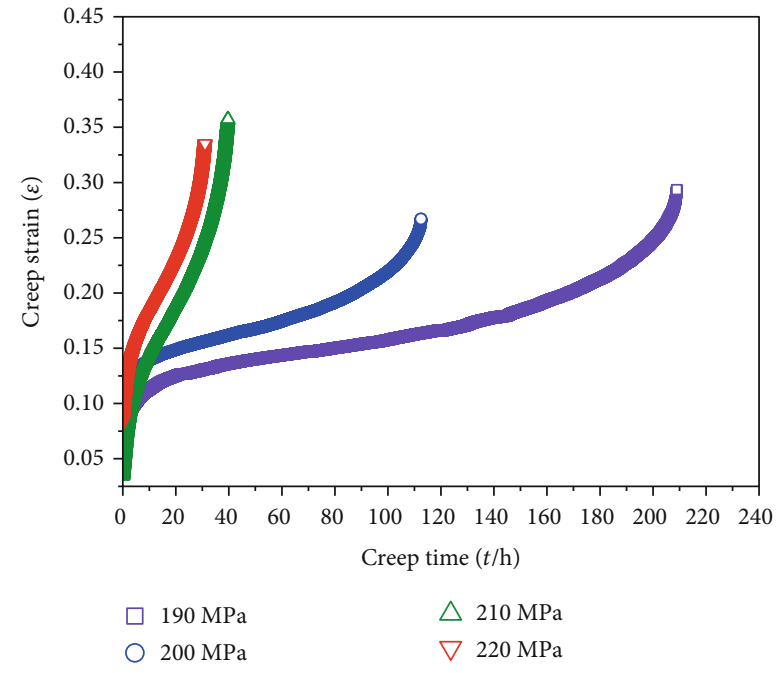

(b)

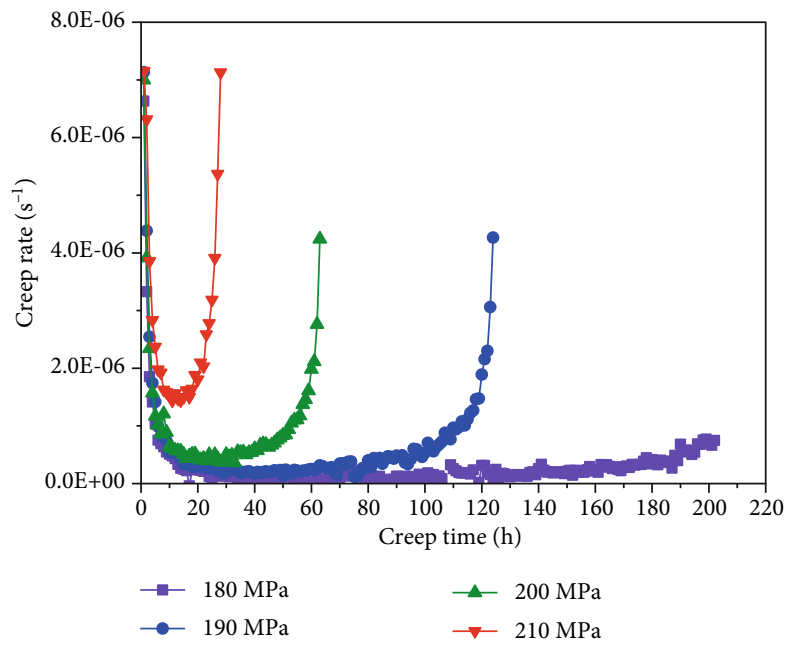

(d)

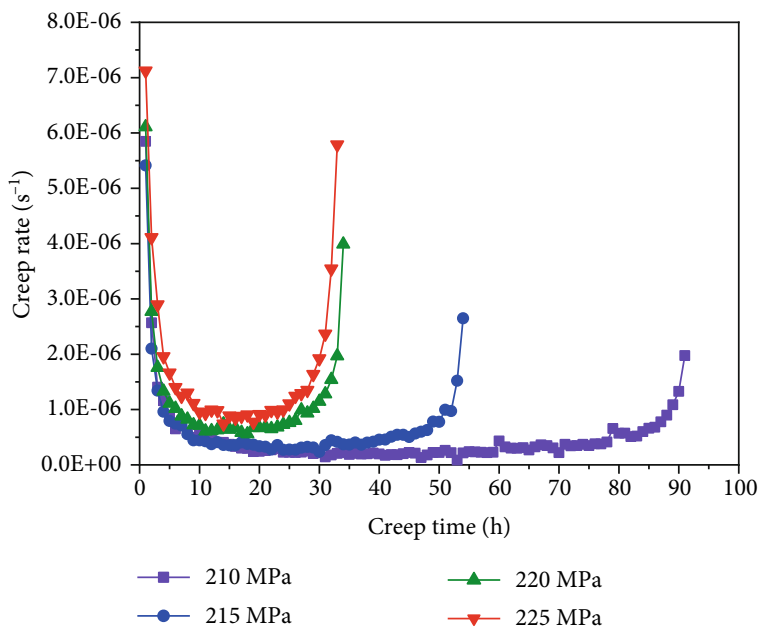

(f)

FIGURE 5: Creep curves and creep rate curves of specimens under different loading stresses: (a) creep curve of aluminized specimen; (b) creep curve of aluminized specimen with single LSP impact; (c) creep curve of aluminized specimen with three LSP impacts; (d) creep rate curve of aluminized specimen; (e) creep rate curve of aluminized specimen with single LSP impact; and (f) creep rate curve of aluminized specimen with three LSP impacts. 


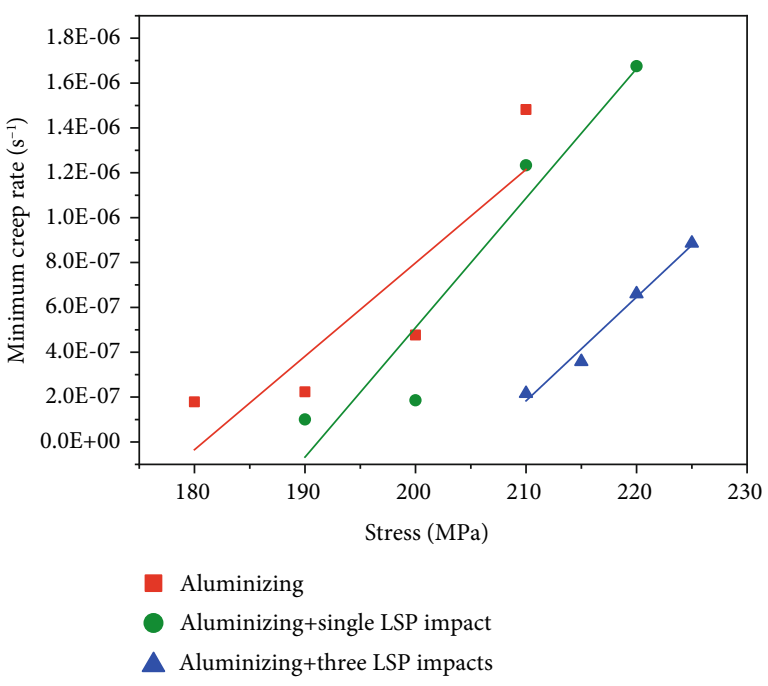

FIGURE 6: Creep rupture strength of 321 stainless steel treated with different surface modification processes examined at $620^{\circ} \mathrm{C}$.

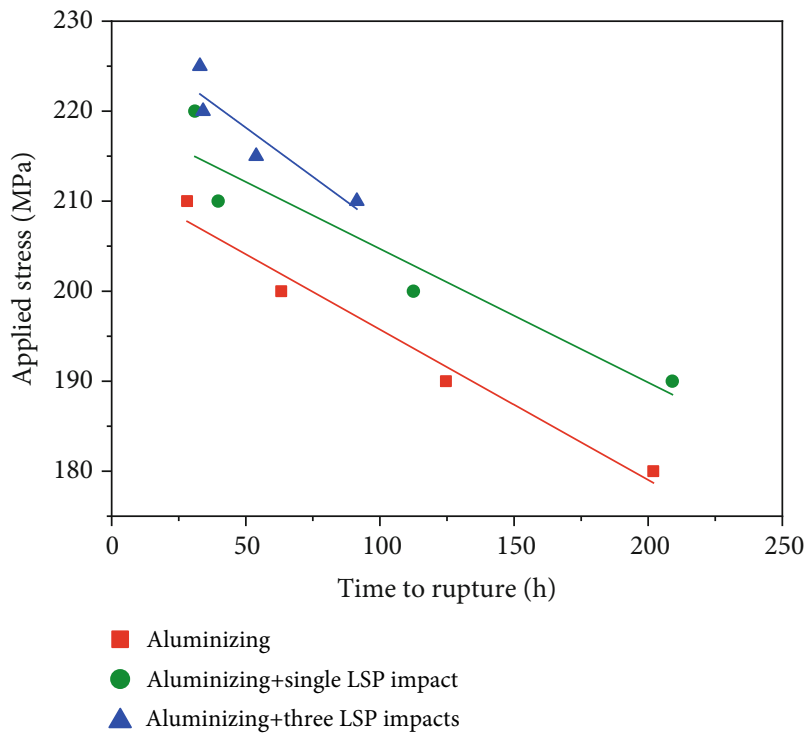

Figure 7: Stress dependence of minimum creep rates for aluminized specimens at different surface modification processes.

austenitic stainless-steel matrix layer. The second phase generated from aluminizing had a large separation tendency from the matrix, which is easily affected by high-temperature environment and the tensile stress. Then, the tendency led to the generation of macropores and eventually fracture. On the one hand, grains of the aluminized layer were refined by the LSP treatment (Figure 9(b)). The rough second phase was evenly distributed on the substrate and the pores' size was narrowed, so that microcracks were difficult to generate. In addition, the laser shock-induced residual compressive stress prevents further creep slips and the separation between crystals. On the other hand, under the impact of high-power lasers, strenuous plastic deformation (Figure 9(c)) accelerates the generation of crystal substructures, changes the direction of grains, and increases the dislocation density. High-density dislocations undergo disorder and discretional slips in all

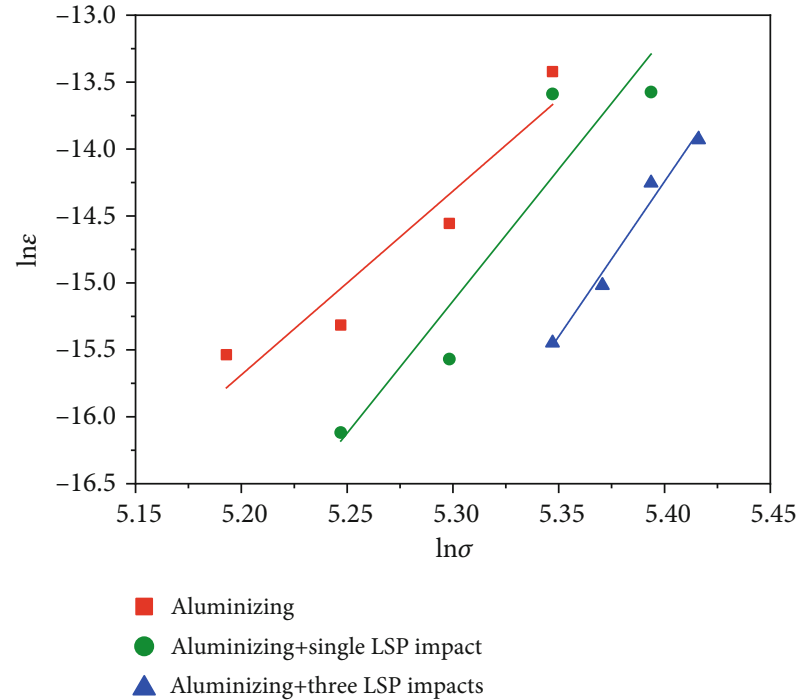

FIGURE 8: Double logarithmic relationship of creep rate and stress for aluminized specimens at different surface modification processes.

directions at high temperatures to annihilate dislocations with particularly slip orientations. This kind of interaction consumes most time and heat to extend the anticreep life of samples [46]. At the same time, high-density dislocations induce significant differences in orientation amongst grain boundaries, resulting in higher internal stresses impeding dislocations, suppressing grain boundary slippage, and delaying the growth of grains to effectively retard crack initiation [47]. The advance in impact times brings out more obvious grain refinement and plastic deformation; therefore, the creep life of the laser-shocked sample with multiple impacts is vitally improved.

The mechanism of creep damage is the exfoliation, formation, and development of voids followed by the occurrence of failure, which attributes to the plastic deformation incompatibility between intragranular inclusions or second phases and matrix radically. The voids are circular or polygonal, dispersing at the intersection of three grain boundaries or on the grain boundary mainly, where the austenite stainless steel voids preferentially nucleate on the inclined grain boundary [48]. Through connected to one another, some hollows turn into a chain eventually, indicating that the voids formed independently intersect with their growth mutually. In particular, as nucleation centers, inclusion particles are contained in some voids. As can be seen from Figures 10(a) and 10(b), dimples and intergranular cracks are visible in the propagation region. Besides, there are several fracture edges' dimple accumulation, secondary cracks, and parallel stripe structures around. After initiating along grain boundaries, the cracks stretch rapidly and converge into larger cracks during the creep process, leading to the separation among grains. Although creep fractures occur at the grain boundaries predominantly, the creep rupture is influenced by the state, structure, and precipitates of the grain boundary seriously. As described in Figures 10(c) and 10(e), the dimples as well as voids are degraded in size and density with increasing times of LSP impact. Meanwhile, neither rough 


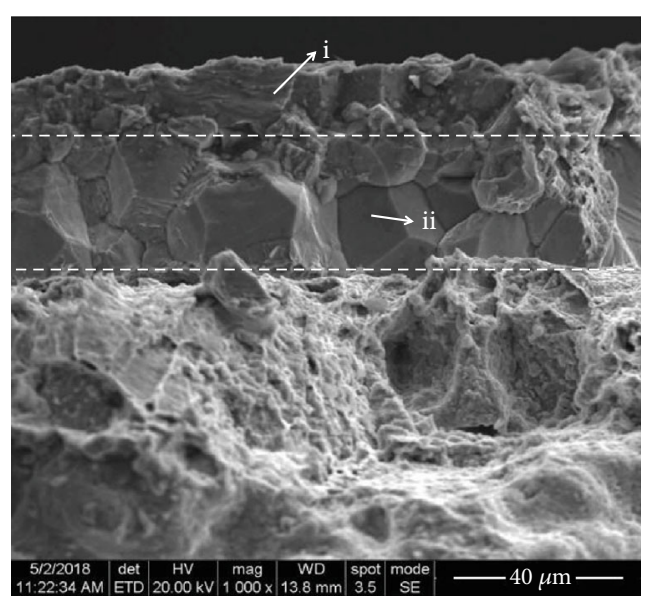

(a)

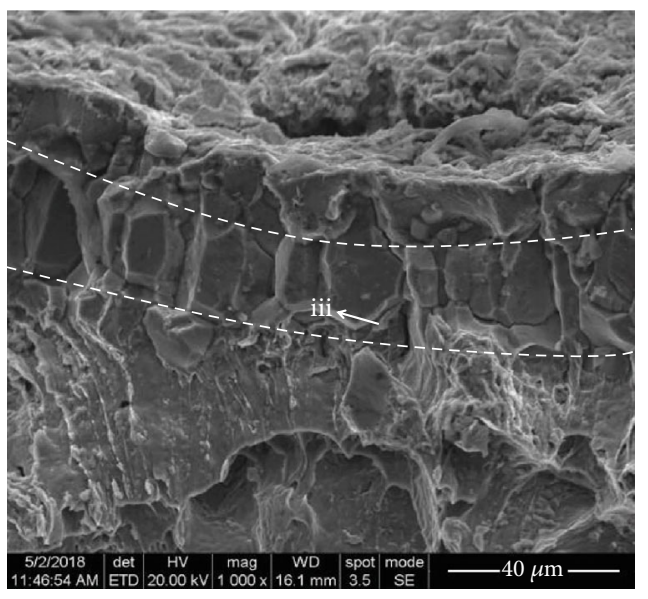

(c)

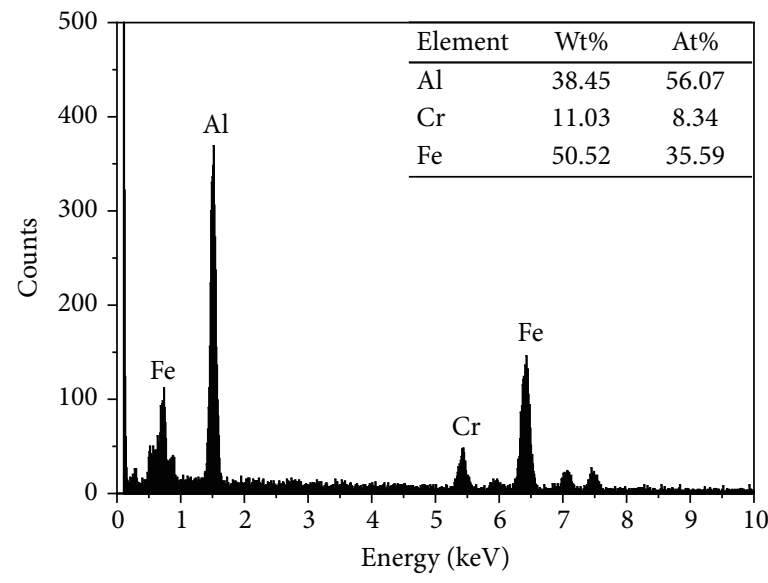

(e)

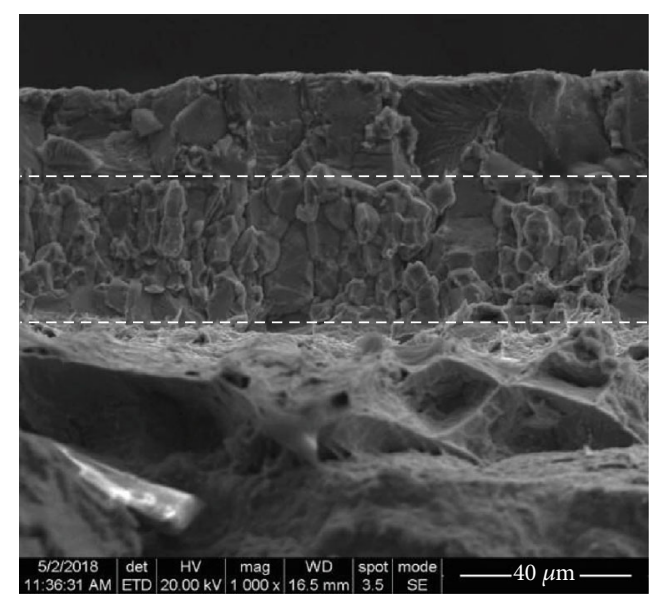

(b)

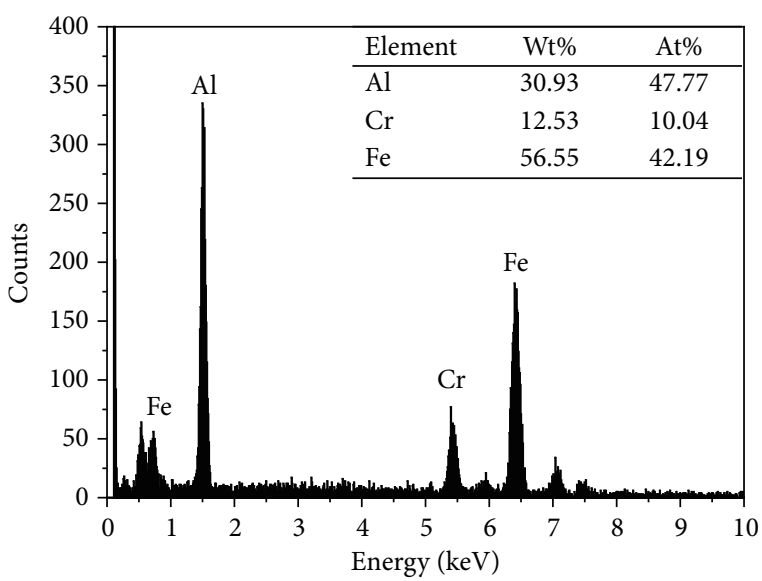

(d)

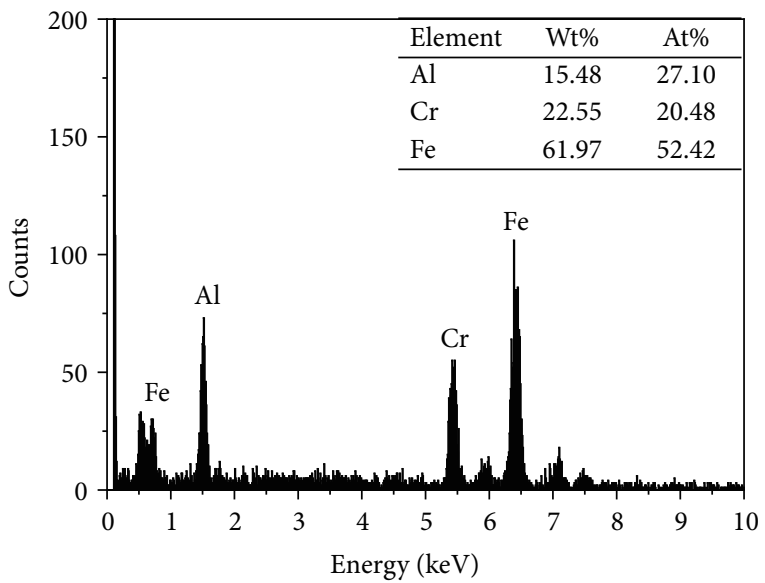

(f)

FIGURE 9: SEM morphology and EDS analysis of fracture surfaces: (a) aluminized steel; (b) aluminized steel with single LSP impact; (c) aluminized steel with three LSP impacts; (d) EDS spectrums of point i in (a); (e) EDS spectrums of point ii in (a); (f) EDS spectrums of point iii in (c).

second-phase particles nor inclusions are observed at magnification (Figures 10(d) and 10(f)). The phenomenon that the fracture toughness of the aluminized steel increases with LSP impacts could be attributed to the rough second-phase particles (or inclusions) with low plasticity, which cannot codeform with the matrix at the same time, resulting in stress 


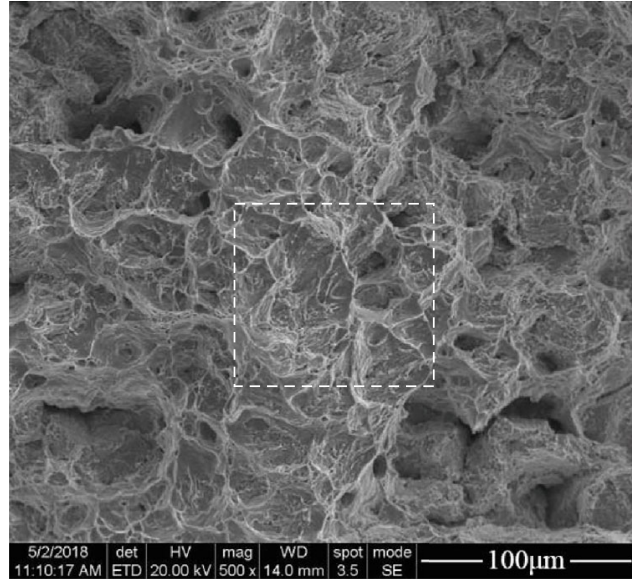

(a)

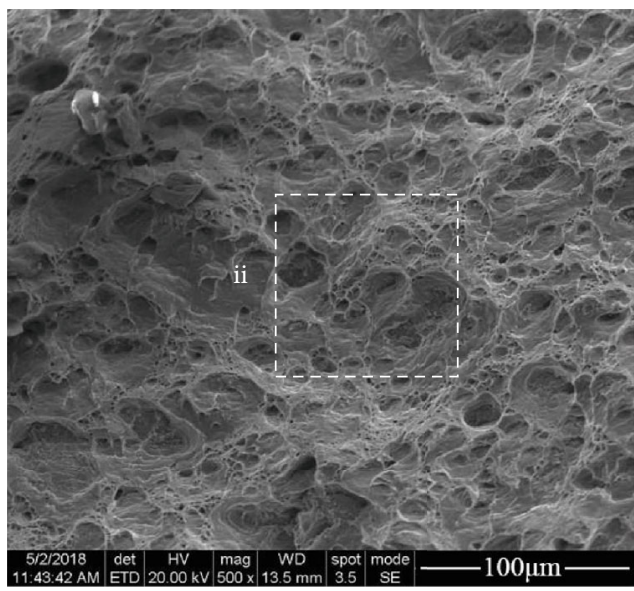

(c)

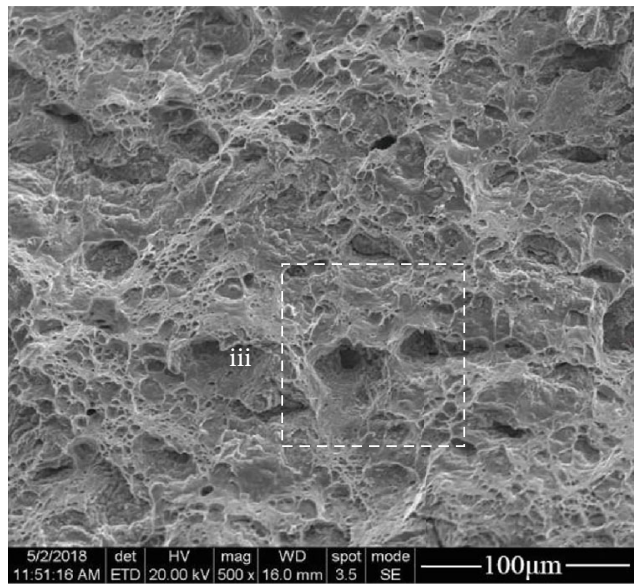

(e)

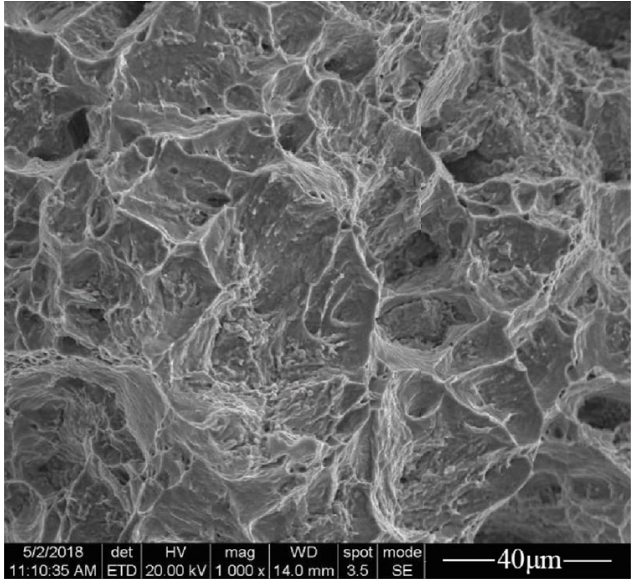

(b)

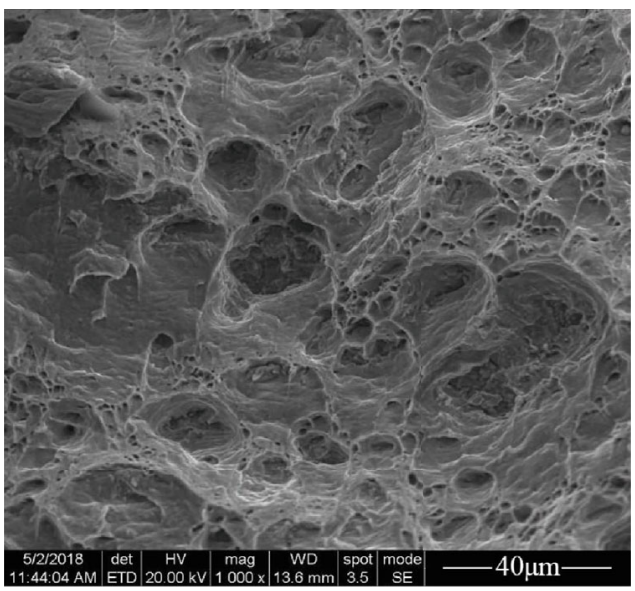

(d)

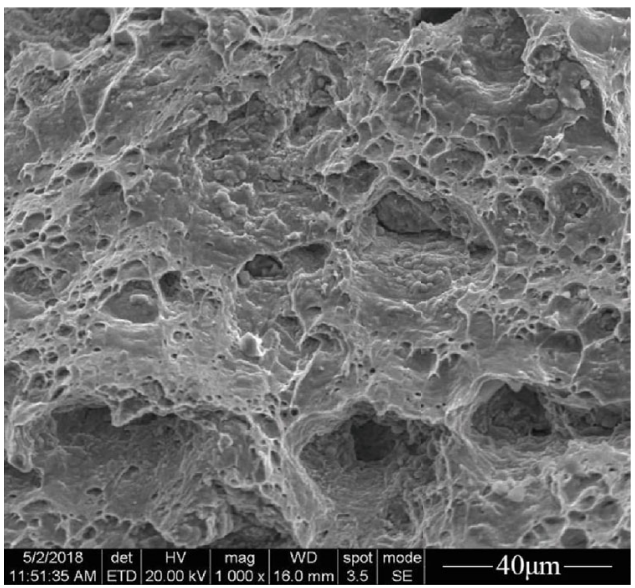

(f)

FIGURE 10: SEM fracture micrographs of the aluminized steel with different impact times of LSP under the stress of $210 \mathrm{MPa}$ (a) aluminized steel; (b) aluminized steel with single LSP impact; (c) aluminized steel with three LSP impacts; (d) magnification of area i; (e) magnification of area ii; and (f) magnification of area iii.

concentrations around particles to cause breakage. Nevertheless, the grain size of the second-phase particles (or inclusions) in aluminized samples with LSP impacts is significantly refined, and the degree of stress concentration is reduced to enhance the creep resistance. In addition, the austenite stainless steel is subjected to soften during the high-temperature aluminizing process, leading to grain coarsening and plasticity deterioration. But grain refinement increased plasticity after LSP, the plasticity of materials is closely related to creep behaviors. Therefore, the impact of laser on the grain refinement of the aluminized steel is the microscopic reason for the improvement in creep performance. 


\section{Conclusion}

In this study, the effect of laser shock processing and aluminizing on microstructure and high-temperature creep properties of the 321 stainless steel were investigated. The main conclusions are described as follows:

(1) A tightly bounded dense iron-aluminum coating was obtained on the surface of the 321 austenitic stainless steel by powder-embedded aluminizing. The roughness, surface plastic deformation, and surface microhardness of the aluminized specimens were significantly increased after LSP treatment, and the strengthening effect of aluminizing specimens with LSP three times is most obvious

(2) Specimens with different impact times of LSP have similar curve shapes to characterize the three stages of typical creep behaviors. The steady-state creep rate decreased and creep rupture time extended with the increase of impact times, which clearly demonstrates that the high-temperature creep resistance of aluminized samples is significantly improved by LSP technology. The $n$ values of aluminizing and aluminizing composite single and three times LSP samples are $13.73,19.71$, and 23.13 respectively

(3) The dimple size, void size, and density of impacted samples became smaller than those of nonimpacted samples. As the number of LSP increases, the dislocation density and the plasticity of material increase because of the more obvious grain refinement and plastic deformation on the surface, which comprehensively improves the creep performance of the aluminized steel

\section{Data Availability}

All data used to support the findings of this study are included within the article.

\section{Disclosure}

An earlier version of this paper was partly presented in terms of an invited report at the $25^{\text {th }}$ Congress of International Federation for Heat Treatment and Surface Engineering (http://www.25ifhtse.csp.escience.cn/dct/page/70051).

\section{Conflicts of Interest}

The authors declare that there is no conflict of interest regarding the publication of this paper.

\section{Acknowledgments}

The authors received financial support from the National Natural Science Foundation of China (No. 51675058 and No. 51801062), the Key Scientific Research Project of the Education Department of Hunan Province (No. 16A002), the Science and Technology Innovation Project of Hunan Province (No. 2018RS3073) and the Hunan Natural Science
Foundation (No. 2018JJ3531), and the double first-class scientific research international cooperation project of Changsha University of Science and Technology (No. 2019IC15).

\section{References}

[1] S. Mihoub, A. Chermiti, and H. Beltagy, "Methodology of determining the optimum performances of future concentrating solar thermal power plants in Algeria," Energy, vol. 122, pp. 801-810, 2017.

[2] S. Kuravi, J. Trahan, D. Y. Goswami, M. M. Rahman, and E. K. Stefanakos, "Thermal energy storage technologies and systems for concentrating solar power plants," Progress in Energy and Combustion Science, vol. 39, no. 4, pp. 285-319, 2013.

[3] C. Li, J. Chen, W. Li et al., "Study on the relationship between microstructure and mechanical property in a metastable $\beta$ titanium alloy," Journal of Alloys and Compounds, vol. 627, pp. 222-230, 2015.

[4] C. Li, J. Chen, Y. J. Ren, W. Li, J. J. He, and J. H. Chen, “Effect of solution heat treatment on the stress-induced martensite transformation in two new titanium alloys," Journal of Alloys and Compounds, vol. 641, pp. 192-200, 2015.

[5] C. Li, J. Chen, W. Li, Y. J. Ren, J. J. He, and Z. X. Song, "Effect of heat treatment variations on the microstructure evolution and mechanical properties in a $\beta$ metastable Ti alloy," Journal of Alloys and Compounds, vol. 684, no. 5, pp. 466-473, 2016.

[6] W. Li, J. Chen, H. Liang, and C. Li, "Research on hightemperature compression and creep behavior of porous $\mathrm{Cu}$ $\mathrm{Ni}-\mathrm{Cr}$ alloy for molten carbonate fuel cell anodes," Materials Science-Poland, vol. 33, no. 2, pp. 356-362, 2015.

[7] J. Wang, Y. Lin, J. Yan et al., "Influence of time on the microstructure of AISI 321 austenitic stainless steel in salt bath nitriding," Surface \& Coatings Technology, vol. 206, no. 15, pp. 3399-3404, 2012.

[8] Y. J. Ren, Y. Q. Chen, J. Chen, W. Li, and C. L. Zhang, "Electrochemical impedance studies for intergranular corrosion of super $304 \mathrm{H}$ stainless steel," Materials Performance, vol. 55 , no. 8 , pp. 60-63, 2016.

[9] C. Li, J. Chen, W. Li et al., "Investigation on compressive behavior of $\mathrm{Cu}-35 \mathrm{Ni}-15 \mathrm{Al}$ alloy at high temperatures," Materials Science-Poland, vol. 32, no. 3, pp. 341-349, 2014.

[10] K. Guan, X. Xu, H. Xu, and Z. Wang, "Effect of aging at $700{ }^{\circ} \mathrm{C}$ on precipitation and toughness of AISI 321 and AISI 347 austenitic stainless steel welds," Nuclear Engineering and Design, vol. 235, no. 23, pp. 2485-2494, 2005.

[11] R. K. C. Nkhoma, C. W. Siyasiya, and W. E. Stumpf, "Hot workability of AISI 321 and AISI 304 austenitic stainless steels," Journal of Alloys and Compounds, vol. 595, no. 13, pp. 103-112, 2014.

[12] X. Xiang, X. Wang, G. Zhang, T. Tang, and X. Lai, "Preparation technique and alloying effect of aluminide coatings as tritium permeation barriers: a review," International Journal of Hydrogen Energy, vol. 40, no. 9, pp. 3697-3707, 2015.

[13] W. Li, J. Chen, J. J. He et al., "Effect of the sic particle orientation anisotropy on the tensile properties of a spray-formed Sicp/Al-Si composite," Strength of Materials, vol. 46, no. 2, pp. 221-228, 2014.

[14] K. Singh, A. Fernandes, B. Paul, M. R. Gonal, G. Abraham, and N. Krishnamurthy, "Preparation and investigation of aluminized coating and subsequent heat treatment on $9 \mathrm{Cr}-1 \mathrm{Mo}$ 
Grade 91 steel," Fusion Engineering and Design, vol. 89, no. 11, pp. 2534-2544, 2014.

[15] M. Mollard, B. Rannou, B. Bouchaud, J. Balmain, G. Bonnet, and F. Pedraza, "Comparative degradation of nickel aluminized by slurry and by pack cementation under isothermal conditions," Corrosion Science, vol. 66, no. 1, pp. 118-124, 2013.

[16] S. Guo, Z. B. Wang, L. M. Wang, and K. Lu, "Lower-temperature aluminizing behaviors of a ferritic-martensitic steel processed by means of surface mechanical attrition treatment," Surface \& Coatings Technology, vol. 258, no. 1, pp. 329-336, 2014.

[17] W. Krauss, J. Konys, and S. E. Wulf, "Corrosion barriers processed by $\mathrm{Al}$ electroplating and their resistance against flowing Pb-15.7Li," Journal of Nuclear Materials, vol. 455, no. 1-3, pp. 522-526, 2014.

[18] S. Majumdar, B. Paul, V. Kain, and G. K. Dey, "Formation of $\mathrm{Al}_{2} \mathrm{O}_{3} / \mathrm{Fe}$-Al layers on SS 316 surface by pack aluminizing and heat treatment," Materials Chemistry and Physics, vol. 190, pp. 31-37, 2017.

[19] S. W. Green and F. H. Stott, "Aluminizing of iron-nickel-base alloys for resistance to high-temperature gaseous environments," Corrosion Science, vol. 23, no. 15, pp. 345-359, 1992.

[20] W. J. Cheng and C. J. Wang, "Study of microstructure and phase evolution of hot-dipped aluminide mild steel during high-temperature diffusion using electron backscatter diffraction," Applied Surface Science, vol. 257, no. 10, pp. 46634668, 2011.

[21] A. R. Rastkar and N. Rezvani, "The effects of processing time on the microstructure and composition of plasma packaluminized and -oxidized surface layers on low carbon steel," Metallurgical and Materials Transactions A, vol. 46, no. 9, pp. 4132-4142, 2015.

[22] S. Dryepondt, Y. Zhang, and B. A. Pint, "Creep and corrosion testing of aluminide coatings on ferritic-martensitic substrates," Surface \& Coatings Technology, vol. 201, no. 7, pp. 3880-3884, 2006.

[23] B. L. Bates, Y. Zhang, S. Dryepondt, and B. A. Pint, "Creep behavior of pack cementation aluminide coatings on Grade 91 ferritic- martensitic alloy," Surface \& Coatings Technology, vol. 240, no. 3, pp. 32-39, 2014.

[24] K. Kakehi, F. H. Latief, and T. Sato, "Influence of primary and secondary orientations on creep rupture behavior of aluminized single crystal Ni-based superalloy," Materials Science and Engineering A, vol. 604, no. 604, pp. 148-155, 2014.

[25] J. L. Ocaña, M. Morales, J. J. García-Ballesteros, J. A. Porro, O. García, and C. Molpeceres, "Laser shock microforming of thin metal sheets," Applied Surface Science, vol. 255, no. 10, pp. 5633-5636, 2009.

[26] Y. J. Ren, W. Wen, J. Chen, J. L. Chen, W. Qiu, and J. J. He, "Corrosion behaviour of nanochromium coatings deposited by direct current magnetron sputtering," Surface Engineering, vol. 32, no. 4, pp. 294-298, 2016.

[27] X. Wu, C. Huang, X. Wang, and H. Song, "A new effective method to estimate the effect of laser shock peening," International Journal of Impact Engineering, vol. 38, no. 5, pp. 322329, 2011.

[28] W. Li, J. Chen, Y. Hu, L. Cong, Y. P. Sun, and J. M. Yang, "Cyclic fatigue fracture behavior of spray-deposited SiCp/AlSi composite," Journal of Materials Engineering and Performance, vol. 23, no. 8, pp. 2871-2876, 2014.
[29] P. Yella, P. Venkateswarlu, R. K. Buddu et al., "Laser shock peening studies on SS316LN plate with various sacrificial layers," Applied Surface Science, vol. 435, pp. 271-280, 2018.

[30] C. A. Vázquez Jiménez, G. Gómez Rosas, C. Rubio González, V. Granados Alejo, and S. Hereñú, "Effect of laser shock processing on fatigue life of 2205 duplex stainless steel notched specimens," Optics Laser Technology, vol. 97, pp. 308-315, 2017.

[31] J. Z. Lu, J. S. Zhong, K. Y. Luo et al., "Strain rate correspondence of fracture surface features and tensile properties in AISI304 stainless steel under different LSP impact time," Surface \& Coatings Technology, vol. 221, no. 16, pp. 88-93, 2013.

[32] Z. L. Lai, "Effects of laser shock peening and ultrasonic shot peening on fatigue property of $1 \mathrm{Cr} 11 \mathrm{Ni} 2 \mathrm{~W} 2 \mathrm{MoV}$ stainless steel," Laser \& Optoelectronics Progress, vol. 50, no. 5, 2013.

[33] B. P. Fairand and A. H. Clauer, "Laser generation of highamplitude stress waves in materials," Journal of Applied Physics, vol. 50, no. 3, pp. 1497-1502, 1979.

[34] L. Sihai, H. Weifeng, Z. Liucheng, N. Xiangfan, and L. Yinghong, "Aluminizing mechanism on a nickel-based alloy with surface nanostructure produced by laser shock peening and its effect on fatigue strength," Surface \& Coatings Technology, vol. 342, pp. 29-36, 2018.

[35] W. Li, Y. Ning, J. Chen, Y. Sun, Y. Hu, and J. He, "Investigation on microstructure and fatigue characteristics of spray-formed SiCp/Al-20Si composite," Transactions of the Indian Institute of Metals, vol. 68, no. 5, pp. 769-775, 2015.

[36] W. Li, Y. Ning, J. Chen, Y. P. Sun, and C. Li, "Effect of SI content on microstructure and mechanical properties of the sprayformed SiCp/Al-Si composites," Powder Metallurgy and Metal Ceramics, vol. 54, no. 5-6, pp. 298-303, 2015.

[37] J. M. Yang, Y. C. Her, N. Han, and A. Clauer, "Laser shock peening on fatigue behavior of 2024-T3 Al alloy with fastener holes and stopholes," Materials Science and Engineering A, vol. 298, no. 1-2, pp. 296-299, 2001.

[38] A. L. Wen, S. W. Wang, R. M. Ren, and X. X. Yan, "Effect of combined shot peening process for surface nanocrystallization method on fatigue strength of TC4," Advanced Materials Research, vol. 97-101, pp. 2217-2220, 2010.

[39] G. Wang and P. Liaw, Fatigue and fracture behavior, Bulk Metallic Glasses Springer US, 2008.

[40] Y. L. Huang, F. H. Yang, G. Y. Liang, and J. Y. Su, "Using insitu technique to determine laser absorptivity of Al-alloys," Chinese Journal of Lasers, vol. 30, no. 5, pp. 449-453, 2003.

[41] F. Z. Dai, J. Z. Lu, Y. K. Zhang, D. P. Wen, X. D. Ren, and J. Z. Zhou, "Surface integrity of micro-dent arrays fabricated by a novel laser shock processing on the surface of ANSI 304 stainless steel," Vacuum, vol. 106, no. 5, pp. 69-74, 2014.

[42] Y. Xiong, H. Y. He, K. Y. Luo, G. Zhiqiang, L. Yanjun, and Z. Lingfeng, "Effect of laser shock processing times on microstructure and microhardness of high carbon pearlitic steel," Chinese Journal of Lasers, vol. 40, no. 4, 2013.

[43] Z. Ying, F. Bowen, G. Wei, and K. Hui, "Influence of laser shock peening times on microstructure and hardness of TA15 titanium alloy," Journal of Beijing University of Aeronautics \& Astronautics, vol. 40, no. 4, pp. 444-448, 2014.

[44] M. Pekguleryuz and M. Celikin, "Creep resistance in magnesium alloys," International Materials Reviews, vol. 55, no. 4, pp. 197-217, 2010. 
[45] J. Tian and Z. Q. Shi, "Creep mechanism and creep constitutive model of aluminum silicate short-fiber- reinforced magnesium matrix composite," Transactions of Nonferrous Metals Society of China, vol. 24, no. 3, pp. 632-640, 2014.

[46] W. Li, H. Weifeng, L. Yinghong, W. Cheng, and Y. Zhuojun, "Effects of laser shock processing on vibration fatigue properties of K417 material," Chinese Journal of Lasers, vol. 36, no. 8, pp. 2197-2201, 2009.

[47] N. Tao, W. Tong, Z. Wang et al., "Mechanical and wear properties of nanostructured surface layer in iron induced by surface mechanical attrition treatment," Journal of Materials Science and Technology, vol. 19, no. 6, pp. 563-566, 2003.

[48] Y. Yang, A. Shan, and D. Lin, "High temperature deformation and fracture of Fe 3Al Ti," Journal of Shanghai College of Metallurgy, vol. 20, no. 3, 1999. 